\title{
Bleeding in Jail: Objectification, Self-Objectification, and Menstrual Injustice
}

\author{
Tomi-Ann Roberts
}

Between 20 and 60 female inmates are strip-and body-cavity searched in an outdoor bus garage with no privacy partitions, near the County Jail, upon booking and/or return from any medical appointments or court hearings. The strip- and body-cavity searches are conducted publicly (that is, en masse) and monitored by female deputies. The inmates stand together, sometimes in very close proximity to or even in physical contact with one another, and within view of one another during the procedure. While in this bus port, the women must remove their clothing and are told to lift their breasts and bellies, and then to bend over and spread their buttocks and labia to expose their rectums and vaginas for inspection with a flashlight. Women who are menstruating must remove their soiled tampons or menstrual pads in front of the entire group. In some cases, either because of heavy bleeding, or because they must stand long enough after removal of their menstrual products, women bleed down their legs and onto the floor of the bus port during the procedure. This occurs in the view of other inmates and of jail staff involved in the search process.

In 2015, I received an intriguing email from a young civil rights lawyer in Los Angeles, California, explaining that her firm was litigating a case challenging the way female detainees are strip searched. She provided me the above description of the procedure and asked whether I would be willing to serve as an expert for their class action. My first reaction to this request was frankly disbelief. When I called, I found I could neither fathom that this "procedure" was actually legal and that thousands of women had undergone it, nor that it should take "expertise" (mine, or anyone's) to convince a judge that such treatment violates the most basic of human rights to bodily integrity, dignity, and privacy. But she assured me that the procedure is indeed legal under California law and an expert was indeed needed to strengthen 
their case. The firm wished me to address how women are socialized to view menstruation as personal, private, and even disgusting, and how these socio-cultural attitudes contribute to feelings of shame and degradation when women are forced to remove soiled feminine hygiene products and potentially bleed openly in a large group setting.

I agreed to write a report based on the psychological science and philosophy of objectification, in which I argued that, among the many psychic consequences of self-objectification can be deeply negative attitudes toward the body's more corporeal features, including menstruation. These are revealed in women's own shame and self-disgust regarding their periods, which this degrading strip and body cavity search procedure only amplifies among the jailed inmates to the point of abject mortification.

I was not permitted in my expert report to speak much at all to the treatment of the inmates by the deputies for two reasons. First, the strip and body cavity search procedure as such is and will remain legal under California law. Our dispute was with the conditions under which it takes place-en masse in full view of others, and in a poorly maintained, potentially unsanitary setting (the bus port next door to the County Jail). Secondly, what we know of many deputies' abusive, shaming verbal commentary to the inmates during the procedure comes via inmate declarations, and hence is second-hand. But what I was not permitted to discuss in my report, I am eager to examine in this chapter. ${ }^{1}$

I will explore more in depth the issues raised around the problematic emotions of shame and disgust that ensue when we do as objectification and self-objectification ask of us, which is to repudiate our own or others' animal, biological bodies. First, I establish the theoretical background of objectification and self-objectification that informed my report. Next, I address research supporting the argument that deep shame and self-disgust is inevitably engendered in the inmates themselves who were subjected to the invasive procedure in full view of others. Third, I consider how the female deputies' mistreatment via shaming and degradation of the inmates during the procedure is an ironic reflection of their own wish to deny their animality, is therefore immoral, and ought to have no place anywhere, much less in a setting like a jail or prison where menstruators are already bereft of so-called "creature comforts." Fourth, I address another form of menstrual injustice widely meted out against incarcerated populations- the lack of access to and sometimes even withholding of menstrual management products. And finally, I close with some discomforts and conclusions.

\section{Objectification, Self-Objectification, and the Creaturely Menstruating Body}

Philosopher Martha Nussbaum (1995) described ways in which human beings can be treated as objects, clarifying seven properties of objectification, or the treating of persons as things. These properties include instrumentality, 
denial of autonomy, inertness, fungibility, violability, ownership, and denial of subjectivity. Rae Langton (2009) extended this analysis specifically to the objectification of female bodies, adding three more ways it is revealed: reduction to a body or body parts, focus on appearance, and silencing. The treatment of menstruating incarcerated women during the strip and body cavity search in the Los Angeles County Jail reflects many, if not all, of these properties of objectification.

My colleague Barbara Fredrickson and I offered objectification theory in 1997 to psychological science as a way of framing female embodied experience. We argued that Western cultures are saturated with heteronormative sexuality, and one feature of this is the pervasive evaluation of girls' and women's bodies, their worth primarily determined by their observable features, much in the same way that we might evaluate the worth of everyday, ordinary objects or tools. Such treatment, we posited, occurs along a continuum from the seemingly benign sexualized evaluation of their bodies to more extreme and undeniably brutal sex trafficking or rape (Fredrickson and Roberts 1997). We argued that this cultural milieu of sexual objectification accomplishes a colonization of the mind of many girls and women, who, as a consequence, become their own first surveyors-self-objectifying as a way of anticipating rewards and punishments likely to come from a culture that values their physical appearance above all else (Fredrickson and Roberts 1997; Roberts 2002).

So common as to be virtually normative, one consequence of the culture of sexual objectification and self-objectification is the widespread dissatisfaction women feel with their bodies; here we already see that this strip and body cavity search, involving the exposure of the most private parts of the inmates' bodies in public, would be particularly cruel and punishing for them. $80 \%$ of U.S. women are dissatisfied with how their bodies look, and most racial, ethnic and socioeconomic groups of American women appear to be increasingly similarly dissatisfied (Grabe and Hyde 2006). Women are socialized to value their physical appearance as the single most important element of their self-worth (Fredrickson and Roberts 1997). Because of the proliferation of mass media formats and the $24 / 7$ delivery of these formats, all of us are socialized within this framework of idealized, sexually objectified female bodies (APA 2007). These images are often presented as the "normal" or average body, but they are in fact airbrushed, highly manipulated representations of an ideal. They are a fantasy. The use of these images sends the message that, in order for a woman (cis or trans) to be considered attractive, which is a prerequisite for female personhood, she must make tremendous efforts to look like the now-normalized ideal bodies she is inundated with by the media. This would not be harmful except for the fact that very few actual humans meet this photoshopped cultural ideal. Hence, like most women who aspire to this ideal, I argued that those in the Los Angeles County Jail already felt like failures, even before undergoing the procedure in question, surely setting them up for a more extreme emotional reaction during it. 
Above all else, sexually objectified ideal female bodies are sanitized, hygienic, denuded, and deodorized, that is, devoid of any of the more "creaturely" or animal-like features such as body hair, genitals, or evidence of body products such as mucus or blood. Simone De Beauvoir wrote in The Second Sex, "In women are incarnated disturbing mysteries of nature ... In woman dressed and adorned, nature is present but under restraint . . . A woman is rendered more desirable to the extent that her nature is more rigorously confined" $(1952,84)$. Building from this, my colleague Jamie Goldenberg and I $(2004,2011)$ provided an integration of objectification and terror management theories (for example, Greenberg, Pyszczynski, and Solomon 1986) to help explain the paradox that women's bodies are both idealized as objects of beauty and desire, but also derided for and typically required to regulate many of the creaturely functions of those very bodies. We argued that sexual objectification and self-objectification serve the purpose of distancing us from women's more creaturely functions, which are, ironically, existentially threatening. As Dinnerstein (1976) noted, the very functions that serve human existence-menstruation, birth, lactation - are, by extension, also reminders of human non-existence or mortality. In controlling women's bodies, patriarchal societies in effect control mortality itself. Objectifying and self-objectifying via sanitizing, deodorizing, denuding, dieting, surgery (the list goes on and on) then, serve as a psychic defense against the reminders of our animal (and hence mortal) natures that women's bodies, more than men's, engender.

Therefore, beyond normative body dissatisfaction, likely setting the inmates up for an experience of some discomfort at a minimum, forced to expose their own flawed bodies to deputies and one another, 20 years of research has established myriad far more extremely negative psychic consequences of sexual objectification and self-objectification (Roberts, Calogero, and Gervais 2018) predicted to arise, given this procedure's exposure of menstruating inmates' creaturely bodies to one another. It is to two particularly crushing emotions engendered by sexual and self-objectification-shame and disgust toward one's own corporeal, animal body—that I turn now.

\section{The Inmates: Self-Objectification Yields Self-Disgust AND SHAME}

The emotion of disgust is associated with the action tendency of putting distance between the self and the cause of disgust, which is considered contaminating. And indeed many religious traditions prohibit touching menstruating women, for example, and prescribe ritual cleaning after the period is over (Dunnavant and Roberts 2013). These prescriptions, proscriptions, and rituals reflect a belief that menstrual blood is contaminating. This is, of course, misguided thinking, because menstrual blood is not, in fact, a contaminant, but it is nevertheless deep-seated, because it is rooted in the ancient emotion of disgust. In a study of American mostly secular college students, male and 
female participants showed a disgust-like reaction to a woman who revealed her menstrual status ("accidentally" dropping a tampon out of her handbag) by sitting further away from her and derogating her competence. Participants also endorsed more sexually objectifying attitudes toward women's bodies in general after being reminded of menstruation by the dropped tampon (Roberts et al. 2002).

Self-objectification serves the function for women themselves of psychic distancing from their own creaturely nature, and several studies have found that indeed the more women self-objectify, the more they feel emotions such as disgust and shame toward their bodies' reproductive functioning, including menstruation (for example, Johnston-Robledo et al. 2007; Roberts 2004). Other studies show that women who score higher in self-objectification are more likely to endorse menstrual suppression, arguably a reflection of disgust's action tendency of removal of so-called contaminating entities (Johnston-Robledo et al. 2003). We see these attitudes and emotions reflected in inmates' testimonies about emotions the public strip and body cavity search engendered in them. One inmate stated that during the procedure, having her menstrual status publicly laid bare, made her feel "worthless as a woman," reflecting the ways the forced exposure of her "disgusting" creaturely body tore away the psychic defense of self-objectification that enabled her to be socially acceptable as a woman. Another inmate stated in her deposition: "I refuse to discontinue use of the Depo Provera shot for fear of menstruating at CRDF (the county jail)." This inmate found a way to ensure that her "worthlessness as a woman" would not be revealed during the strip searches because she would not ever have her period during them.

Most societies do not banish menstruating women from the community or otherwise require social quarantine, and most menstruators do not suppress their periods with pharmaceutical interventions, however menstrual management is associated with strong cultural taboos commanding that it not be seen, discussed or openly acknowledged, even among women themselves, reflecting a "concealment imperative" (Wood, this volume). Because of secrecy norms, having one's period is almost never openly acknowledged (Kissling 1996). This reflects the hiding action tendency that is commonly associated with shame. In many low- and middle-income countries, not knowing about menarche or understanding the process of menstruation leads to shame around menstruation, which in turn can lead girls to miss school, self-medicate and refrain from social interaction, effectively quarantining themselves (Chandra-Mouli and Patel 2017).

The menstruating inmates at the Los Angeles County Jail undoubtedly, therefore, felt profound shame, humiliation, and self-disgust during the strip and body cavity search. During the procedure, to determine which inmates would need clean menstrual products, deputies asked them to raise their hand in front of the entire group if they were menstruating, forcing women to "out" themselves to strangers as being on the bleeding days of 
their menstrual cycle. At this point, those having their periods were required to remove tampons or pads or other menstrual products in the presence of the group, and then wait some period of time-until completion of the visual body cavity inspection portion of the search-before replacing them. According to both inmates and deputies, some of the women were heavily bleeding. Given the norms of secrecy, concealment, and sanitation surrounding menstruation, revealing blood to others was surely mortifying. There is also no question that some heavily bleeding inmates would have had to handle heavily saturated tampons. Both deputies and inmates reported observing women drip blood or blood clots onto their legs and/or the ground while waiting to replace tampons or pads.

Statements from the inmates' depositions regarding their feelings during this experience include comments such as: "I felt like a big old hunk of meat," "I felt less than human," and "I felt like an animal," clear reflections of a profound blow to the psychic defenses constructed to keep one's creaturely self in check. These women likely wished they could hide or disappear, a common reaction to intense shame. They were unable to do so, and instead they turned their feelings of worthlessness and dehumanization inward, reporting that they were nothing but hunks of meat or-importantlyanimals. This kind of language reflects a particular form of dehumanization as articulated by Haslam (2006), in which humans are denied uniquely human traits, and seen as animal-like. In animalistic dehumanization, people are considered unrefined, uncouth, incompetent, irrational, and undeserving of moral concern (for example, Loughnan, Haslam, and Kashima 2009).

I wrote in my report that for these women to be left standing with blood on their fingers, legs, and likely even dripping beneath them brings to mind images of the Stephen King novel and movie "Carrie." It would be a truly appalling humiliation, the stuff of the horror genre, inducing disgust in the other women witnessing, and self-disgust and profound shame in the menstruating women themselves, left to stand in their own stigma and "pollution." I further argued that the procedure would be nearly equally as mortifying for inmates who were not actively bleeding, for observing other inmates being required to endure the public exposure of their menstruation would likely have caused extreme anxiety and vicarious shame for them. Vicarious shame occurs when people identify with groups, experiencing emotions on their behalf (Welten, Zeelenberg, and Breugelmans 2012). In this case, even those who were not at that moment bleeding would have strongly identified with those who were, feeling vicarious shame at their public humiliation. Furthermore, the women who were not menstruating would have realized that they could be having their period the next time they were strip searched, and extreme anticipatory anxiety would very likely have ensued. 


\section{The Deputies: Shame and Disgust Are Used to Objectify and Humiliate}

(An) analysis of disgust and shame shows us that human beings typically have a problematic relationship to their mortality and animality, and that this problematic relationship causes not just inner tension, but also aggression toward others. (Nussbaum 2004, 322)

When I read this passage in philosopher Martha Nussbaum's remarkable book Hiding from Humanity: Disgust, Shame and The Law, a framework for understanding the female deputies' abusive treatment of the inmates during the procedure emerged. Beyond the "inner tension" clearly reflected in the nearly 500 inmates' recurring references to feelings of shame, humiliation, and dehumanization, the female deputies' mistreatment via shaming and degradation of the inmates during the procedure is an ironic reflection of their own wish to deny their animality. Nussbaum argues in arenas such as sodomy, abortion, and pornography appeals to common understandings of the "revolting," "repugnant," or "shameful" are made to support law and punishment. However, disgust is irrational. It is based on "magical thinking" regarding contamination and is insensitive to information about actual risk.

Because we fear the disgusting and shameful within ourselves, Nussbaum argues that we cordon off, exclude, and often even punish groups of humans who exemplify animality as a way of elevating ourselves. Throughout history, then, certain disgusting and shameful properties such as smelliness, sliminess, and stickiness (all, incidentally, properties of menstrual blood) are repeatedly and monotonously projected onto certain groups: Jews, LGBTQ persons, Dalits, and women, providing a kind of emotional fuel for Anti-Semitism, homophobia, classism, caste prejudice, and misogyny (Nussbaum 2004).

In the case of the female deputies conducting the strip and body cavity search procedure, Nussbaum's analysis predicts a kind of Freudian reaction formation. That is, if I feel ashamed about my own animality (my knowledge that I, too, menstruate) then one solution is to transform that humiliation into rage-like idealization of myself and denigration of the inmates standing before me, to draw a line between us, and cordon off their polluting, contaminating stickiness away from me. Here is how shame and disgust provided the immoral fuel for the deputies to animalistically dehumanize their fellow female inmates. Indeed examples of deputies deploying disgust to objectify and dehumanize the inmates during the strip and body cavity search procedure abound. Heavier women were asked to "lift their stomachs" away from their genital region to expose it fully. One witness recounted a deputy remarking to another on her belly as she stood there, naked, holding it up and away, in the presence of the group, "Have you ever seen anything like that, how it hangs?"

For the visual body cavity inspection, deputies instructed inmates to turn back toward the wall, drop their underwear, bend over at the waist, reach 
behind their bodies and spread the lips of their labia to expose their vagina and anal aperture so that their body cavities could be inspected, one by one, by deputies using flashlights. In delivering the commands, deputies specifically ordered women to "open their vagina lips." Before doing so, they were told that "if you've got something in your pussy hole, take it out." Inmates reported that deputies yelled at them, criticizing them for not following directions, saying things like, "spread your lips, not your asshole," "spread your pussy lips." Several reported that as heavily bleeding women dripped blood onto their hands, clothing, legs, or on the ground while waiting to replace tampons, deputies derided them and refused to provide anything for cleaning up.

Deputies' testimonies included justifying their abusive language because inmates did not seem to understand them or had difficulty complying with instructions. This reflects animalistic dehumanization, which degrades perceptions of civility, rationality, competence (for example, Bongiorno, Bain, and Haslam 2013). Furthermore, my own and others' research has shown that indeed under conditions of body exposure or objectification, women (but not men) react with feelings of intense body shame and anxiety, which disrupts their cognitive concentration and diminishes their capacity to be effective (Fredrickson et al. 1998; Calogero 2004; Gervais, Vescio, and Allen 2011). It is not surprising that inmates had problems cooperating with the procedure; they were treated like animals. In their exposure of their own sticky, smelly, abject, corporeal bodies, they reminded all in the bus port that we are just animals. Such a reminder was surely flooding for the inmates themselves, and served as a trigger for objectification ("see how it hangs?") and animalistic dehumanization ("your pussy hole!") by the deputies to draw a distinct line between themselves and the inmates.

The elderly, white, male judge said something during the motion for class certification that I addressed in my report. He argued that, since female deputies were responsible for conducting the strip and body cavity search, the public fact of it could not have been meaningfully traumatizing. Indeed, he argued that the procedure was likely akin to how women might behave with one another in a locker room or spa. I will pass over here in silence this judge's seemingly willful naivety about the lengths to which most women and girls go to avoid public exposure of their bodies, even in locker rooms and spas, and the fact that the exposure in this case was forced, not voluntary. Instead I pointed to research that supports the opposite conclusion. Moral disengagement is the process of convincing the self that ethical standards do not apply to oneself in a particular context (Bandura 2016). Studies show that advantageous comparison within one's in-group can disable the mechanism of self-condemnation that would typically hold immoral action in check. In this case, the female deputies could compare themselves as morally superior to the female inmates, who are in jail after all for having broken the law, and this advantageous comparison likely fueled mistreatment during the procedure and even justified for them their own harsh, abusive language as necessary for compliance. 
Secondly, other studies on collective threat show that intra-group hostility can be activated by "poor behavior" on the part of in-group members (Cohen and Garcia 2005). That is, when an in-group member reinforces a negative stereotype, then other in-group members may distance themselves from and even become hostile toward that person. In this case, bleeding inmates were reinforcing the negative stereotypes that abound about women's "monstrous" (that is, inhuman, creaturely, animal-like, out-of-control) bodies (Ussher 2006), likely generating disgust and hostility in the deputies toward them. Cohen and Garcia's (2005) collective threat framework helps explain the irony of the abusive commentary by the deputies who carried out the procedure which exposed the menstruators" monstrous "shame" in the first place. For they are also women who presumably also menstruate, but unlike the inmates, fully clothed ("dressed and adorned," as De Beauvoir put it), were not engaging in the "poor behavior" of reminding all of the negative stereotypes around menstrual status that are a fact of so many women's embodied lives.

\section{Other Menstrual Injustice for Incarcerated Populations}

This case of the abusive strip and body cavity search at the Los Angeles County Jail for women is likely as shocking to most readers as it was to me when I first received the phone call from the civil rights lawyer. But there are other forms of menstrual injustice meted out on incarcerated women with which the public is likely more aware (see Bozelko [Chapter 5] in this volume). One of these is the commonly practiced restricted access to menstrual management products. A study by the Correctional Association of New York revealed that $54 \%$ of women in prison reported insufficient numbers of sanitary pads provided per month, and that these pads are flimsy and ineffective (Kraft-Stolar 2015). Purchasing menstrual products at the commissary typically comes at such a high cost as to be unaffordable by most inmates.

This restricted access was depicted in an episode in season 4 of the wildly popular television show Orange is the New Black. In it, we see inmates constructing makeshift pads and tampons using sleep masks and toilet paper and being dismissed by prison authorities when seeking help. In real life, in 2016, a detainee held on shoplifting charges was brought into a Kentucky courtroom for sentencing without pants, causing outrage in the female judge. The woman's attorney told the judge that she had been denied pants as well as menstrual hygiene products for days (Bever 2016). A video of the judge's phone call, presumably to the jail, asking "what the hell is going on?" while the pants-less woman stood behind a podium, went viral. In 2014, the ACLU of Michigan sued Muskegon County over hazardous and unconstitutional procedures at the county jail, including denial of access for female inmates to clean underwear and feminine hygiene products (ACLU of Michigan 2014). A former inmate testified that when she had her period, a guard-instead of giving her sanitary napkins - warned her that she'd "better not bleed on the floor." 
Though perhaps not as outrageous as the degradation of bleeding inmates being strip searched en masse, I would argue that restricting access to menstrual products as a form of punishment is cut from the same cloth (pun intended). Denying incarcerated menstruators adequate products, facilities, and privacy is driven by the same animal-based dehumanization specifically engendered by objectifying female bodies. Putting the onus on inmates themselves to constrain and control their menstruating bodies as the objectifying culture requires, in a context in which access to the privacy and products typically used to do so is denied, plays a cruel trick on them. For who is to blame for their degradation and humiliation when they appear in court without pants or bleed on the floor of their cell but they themselves for being so "uncivil," for failing to uphold the requirements of sanitation, deodorization and hygiene of their creaturely bodies?

One plaintiff in the Michigan ACLU case regarding severely restricted access to menstrual products and private toilet facilities echoed testimony by our LA County plaintiffs, articulating this point poignantly: “. . . nobody deserves to be forced to live like an animal and be treated like one. We are women deserving of basic respect, sanitary conditions, bodily privacy, and simply to be treated like the women we are" (ACLU of Michigan 2014). To deny menstruating women adequate products and facilities is to treat them like "animals," publicly humiliating them, retaining psychic distance from them as though they are contaminating. Given that the United States is one of the top incarcerators of women in the world, with approximately 220,000 detained (Kajstura 2017), I am quite confident that countless incarcerated menstruators have indeed bled down their legs and onto jail and prison floors because of this denial. Furthermore, based on my own and others' work on objectification and self-objectification, I imagine many who have done so, further reinforce their own dehumanized status in the eyes of jail or prison officials and even the public, who react with disgust to their out-of-control, monstrous, animal bodies.

\section{Discomforts: Naked vs Nude and the Is-Ought Fallacy}

After I turned in my 30-page report to the law firm, I found myself wrestling with many discomforts as a feminist scholar. I knew my arguments about unique bodily privacy concerns for women essentialized gender differences in a way I would not do in my "real" scholarly work. Further, I did not want the world to be arranged in such a way that women's revelation of menstrual status ought to be shameful and degrading. I knew I was arguing it was the case, even though I wished it was not. These discomforts ended up getting thrown in my face, as lawyers for the defense found my testimony in a different case regarding the sexism of a public nudity ordinance requiring females, but not males, over the age of 10 to cover their chests. In that case, I testified that the sexes are not materially different in terms of breasts, that breasts are not genitals, and that therefore compelling one sex to cover their breasts but 
not the other amounts to sexism. The defendants took my testimony from the context of criminalizing women who voluntarily choose to expose their breasts (for example, while breastfeeding) and applied it to the context of compelling incarcerated women to publicly expose not only their breasts but their genitals, including while menstruating. I had to write a supplemental declaration in which I argued that my testimony in the two cases was completely consistent - to the extent women wish to voluntarily challenge gender stereotypes by exposing their breasts (or, I add here, their menstrual blood, as women such as Rupi Kaur and others in the "free bleed movement" have done) they should have that freedom, but they should never be forced to do so, especially given the shaming associated with such exposure.

Allow me to take a brief detour to Finland, where I spent much of my growing up, and where I imagine these distinctions between forced and voluntary exposure are perfectly obvious, because the distinction between the nude and the naked body is clear there. In Finland, where families and even strangers sit together naked in the sauna, the distinction art historian John Berger (1972) made between naked and nude is in high relief. He argued that to be naked is simply to be without clothes on, whereas to be nude is to have one's body put on display for scrutiny, commodification, or sexualization by others. In the sauna, people are not nude. They are naked, the better to sweat and experience the delights of a cold plunge all over the body. Sometimes extended families split up sauna time by gender. The girls and women go together, and the boys and men go together. My memories of gender-based sauna are some of the most cherished of my childhoodsitting naked alongside my younger sister and same aged cousins, older aunts, and my mother, and still older great aunts and my grandmother. Disgust and shame have no place in the sauna, because nakedness is not aware of itself. Here the naked truths of embodied living are revealed. And so here was where I saw what happens to bellies and breasts and vulvas with age and with illness. Here was where I was a witness to how much diversity there is among these precious parts, typically hidden from view, on different bodies. Here was where I learned about menstruating, seeing and asking about the blood on the towel beneath my mother, or the tampon string peeking out from between the labia of one of my aunts.

With this as my background, I found myself railing against the lawyers for the defense twisting my words, and also wishing that the Judge's presumption regarding women's open nakedness with one another was not ridiculous, but instead was true. If only it were the norm to be in non-self-conscious, naked togetherness, even changing our menstrual pads, tampons or cups in full view of one another! Indeed, this community-building aspect of menstruation was something that a colleague and I found to be more salient and even treasured among our more religious interviewees (Orthodox Jewish, Muslim, and Hindu) than our non-religiously affiliated ones in a study about attitudes toward menstruation (Dunnavant and Roberts 2013). Women who practice religious rituals of separation or cleansing (for example, mikveh bath) around their periods were ironically less shamed and secretive and more likely 
to feel that menstruation tied them to other women in a meaningful way than non-religious women, whose internalization of menstrual taboos, shame, and self-disgust so often isolate and alienate them from one another.

In writing this report, I was often put in mind of the "is-ought fallacy" (the assumption that because things are a certain way, they should always be that way, or that because something is not happening now it should never happen). Even though it is the case that this way of treating incarcerated women is a uniquely effective humiliation, given all that objectification and self-objectification have wrought in terms of our relationship to the female body, of course I do not think it ought to be so. Even though it ought to be possible for incarcerated menstruators to find it in themselves to stand tall and proudly naked, with their hands on their hips, staring deputies and guards in the eyes and bleeding magnificently down their legs, I see that a lifetime of introjecting shame and disgust toward their bodily, animal selves prevents them from this kind of defiance.

I asserted in my report that research supports the conclusion that strip and body cavity searches present unique privacy concerns for women that arise from socio-cultural representations of their bodies which engender emotions such as shame and disgust which are based not in fact, but in "magical thinking" about the creaturely process of menstruation. I argued that the experience of the forced violation of the fundamental right to privacy for these inmates was likely one of the most traumatizing of their lives and therefore was cruel and unusual. We won summary judgment regarding the conditions under which the search is conducted. The court ruled that the group strip searches were unconstitutional because privacy partitions always provided a feasible alternative. Although the decision did not fully capture the barbaric nature of the searches, the outcome was in some ways better than we anticipated in that the Court embraced the plaintiffs' most ambitious argument, which was that intrusive searches without privacy partitions violate the constitution (Amador v. Baca 2017, https://www.clearinghouse.net/detail. php?id=14457).

\section{CONCLUSiON}

Disgust and shame are dangerous social sentiments. We should be working to contain these, rather than building our legal world on the vision of human beings that these emotions contain . . . Society would do well to cast disgust and shame into the garbage heap where it would like to cast so many of us. (Nussbaum 2004, 171)

Today the strip and body cavity search procedure at the Los Angeles County Jail itself remains legal and continues to be conducted, only not in the bus port anymore, and for each woman, one by one behind a makeshift "dressing room" constructed of shower curtains. So though we technically won the case, and all bodies deserve privacy, the victory feels pyrrhic to me, 
because as I type this, I am quite certain that those privacy partitions are not doing much to address the internalized shame and self-disgust about their "monstrous," bleeding bodies the inmates are surely feeling during their procedure, and I imagine the deputies have already found creative ways to degrade the inmates from the other side of them.

In breaking news, as I was making my final edits to this chapter, the Los Angeles Times (Tchekmedyian 2019) reported that the parties have reached a settlement in which Los Angeles County will pay $\$ 53$ million. Most of this will be paid as restitution to the thousands of women in the class who endured the procedure, and some will pay consultants to evaluate the whole strip and cavity search ordeal in light of the fact that such a high percentage of incarcerated women have histories of physical and sexual abuse. However, no sooner did I read this article than I received a phone call from another civil rights law firm in Chicago asking me to join in an amicus brief to help rectify a decision in the Seventh Circuit on prison/jail strip searches. The case in question was again a mass strip search of 200 women who were forced to undergo visual body cavity inspections in groups, naked, again with no accommodations for those who were menstruating. However, here they were rounded up by correctional officers in riot gear and wielding batons, and the ordeal was not done in the name of security, but as a gratuitous training exercise for incoming correctional officer cadets. As I typed my reply of "yes, count me in for this amicus brief" to the lawyer, I glanced at the poster in my office to renew my strength. It reads: "The work continues. Stay fierce."

My involvement in this case opened my eyes, and I hope this chapter will open others' eyes, to the ways in which the shame and disgust about our animal nature that menstruation engenders gets deployed inequitably in the service of a punishing debasement of disenfranchised women. This is a uniquely misogynist form of punishment, meted out against bodies and minds that have been colonized by objectification and self-objectification. We are far from there yet, but I yearn for a day when menstruation might no longer be the stigmatizing "mark" (Johnston-Robledo and Chrisler 2013) it is, both reflecting and contributing to women's lower social, political, and often even moral status, and providing the grotesquely ideal platform for this way to dehumanize those of us who landed on the wrong side of the law and who live in bodies that menstruate.

\section{Note}

1. This chapter uses statements made by women who had been detained in the L.A. County Jail, which I obtained through my role as expert witness in the Amador v. Baca case. The law firm which provided these inmate declarations, Kaye, McLane, Bednarski \& Litt, confirmed that the statements could also be used for the purposes of this chapter. As the statements were completely anonymized and I never personally interacted with any of the women quoted, the Institutional Review Board at Colorado College deemed these materials as meeting the criteria for secondary research exemption. 


\section{REFERENCES}

Amador v. Baca. 2017. Civil Rights Litigation Clearing House. University of Michigan Law School. https://www.clearinghouse.net/detail.php?id=14457.

American Civil Liberties Union of Michigan. 2014. "ACLU of Michigan Sues Muskegon County over Unconstitutional Policies, Hazardous Conditions at Jail," December 4. http://aclumich.org/article/aclu-michigan-sues-muskegon-county-over-unconstitutional-policies-hazardous-conditions-jail.

American Psychological Association [APA]. 2007. Report of the APA Task Force on the Sexualization of Girls. Washington, DC: American Psychological Association. http://www.apa.org/pi/wpo/sexualization_report_summary.pdf.

Bandura, Albert. 2016. Moral Disengagement: How People Do Harm and Live with Themselves. New York, NY: Worth Publisher.

De Beauvoir, Simone. 1952. The Second Sex. Translated by Howard Madison Parshley. New York, NY: Knopf.

Berger, John. 1972. Ways of Seeing. London: Penguin Books.

Bever, Lindsey. 2016. "She Has No Pants and She Is in Court: Judge Outraged over Inmate's Appearance." Washington Post, August 4, 2016.

Bongiorno, Renata, Paul G. Bain, and Nick Haslam. 2013. "When Sex Doesn't Sell: Using Sexualized Images of Women Reduces Support for Ethical Campaigns.” PLoS One 8 (12): e83311.

Calogero, Rachel M. 2004. "A Test of Objectification Theory: The Effect of the Male Gaze on Appearance Concerns in Women." Psychology of Women Quarterly 28: $16-21$.

Chandra-Mouli, Venkatraman, and Sheila Vipul Patel. 2017. "Mapping the Knowledge and Understanding of Menarche, Menstrual Hygiene and Menstrual Health among Adolescent Girls in Low- and Middle-Income Countries." Reproductive Health 14. https://doi.org/10.1186/s12978-017-0293-6.

Cohen, Geoffrey, and Julio Garcia. 2005. "'I am Us': Negative Stereotypes as Collective Threats." Journal of Personality and Social Psychology 89: 566-82.

Dinnerstein, Dorothy. 1976. The Mermaid and the Minotaur: Sexual Arrangements and Human Malaise. New York, NY: HarperCollins.

Dunnavant, Nicki, and Tomi-Ann Roberts. 2013. "Restriction and Renewal, Pollution and Power, Constraint and Community: The Paradoxes of Religious Women's Attitudes toward Menstruation." Sex Roles 68: 121-31.

Fredrickson, Barbara, and Tomi-Ann Roberts. 1997. "Objectification Theory: Toward Understanding Women's Lived Experience and Mental Health Risks." Psychology of Women Quarterly 21: 173-206.

Fredrickson, Barbara L., Tomi-Ann Roberts, Stephanie M. Noll, Diane M. Quinn, and Jean M. Twenge. 1998. "That Swimsuit Becomes You: Sex Differences in SelfObjectification, Restrained Eating, and Math Performance." Journal of Personality and Social Psychology 75: 269-85.

Gervais, Sarah J., Theresa K. Vescio, and Jill Allen. 2011. "What You See Is What You Get: The Consequences of the Objectifying Gaze for Women and Men." Psychology of Women Quarterly 35: 5-17.

Goldenberg, Jamie L., and Tomi-Ann Roberts. 2004. "The Beast Within the Beauty: An Existential Perspective on the Objectification and Condemnation of Women." In Handbook of Experimental Existential Psychology, edited by Jeff Greenberg, Sander L. Koole, and Tom Pyszczynski, 71-85. New York: Guilford. 
2011. "The Birthmark: An Existential Account of the Objectification of Women." In Self-Objectification in Women: Causes, Consequences, and Counteractions, edited by Rachel M. Calogero, Stacey Tantleff-Dunn, and J. Kevin Thompson, 77-99. Washington, DC: American Psychological Association Press.

Grabe, Shelly, and Janet Shibley Hyde. 2006. "Ethnicity and Body Dissatisfaction among Women in the United States: A Meta-Analysis." Psychological Bulletin 132: $622-40$.

Greenberg, Jeff, Tom Pyszczynski, and Sheldon Solomon. 1986. "The Causes and Consequences of a Need for Self-Esteem: A Terror Management Theory." In Public and Private Self, edited by Roy F. Baumeister, 189-212. New York: Springer-Verlag.

Haslam, Nick. 2006. "Dehumanization: An Integrative Review." Personality and Social Psychology Bulletin 10: 252-64.

Johnston-Robledo, Ingrid, and Joan C. Chrisler. 2013. "The Menstrual Mark: Menstruation as Social Stigma.” Sex Roles 68: 9-18.

Johnston-Robledo, Ingrid, Kristin Sheffield, Jacqueline Voigt, and Jennifer Wilcox-Constantine. 2007. "Reproductive Shame: Self-Objectification and Young Women's Attitudes toward Their Reproductive Functioning." Women \& Health 46: 25-39.

Johnston-Robledo, Ingrid, Melissa Ball, Kimberley Lauta, and Ann Zekoll. 2003. "To Bleed or Not to Bleed: Young Women's Attitudes toward Menstrual Suppression.” Women and Health 38: 59-75.

Kajstura, Aleks. 2017. “Women's Mass Incarceration: The Whole Pie 2017.” Prison Policy Initiative of the ACLU Campaign for Smart Justice, October 19. https:// www.aclu.org/sites/default/files/field_document/womenprisonreport_final.pdf.

Kissling, Elizabeth. 1996. "Bleeding Out Loud: Communication about Menstruation." Feminism \& Psychology 6: 481-504.

Kraft-Stolar, Tamar. 2015. Reproductive Injustice: The State of Reproductive Health Care for Women in New York State Prisons: A Report of the Women in Prison Project of the Correctional Association of New York. New York, NY: Correctional Association of New York.

Langton, Rae. 2009. Sexual Solipsism: Philosophical Essays on Pornography Objectification. Oxford: Oxford University Press.

Loughnan, Steve, Nick Haslam, and Yoshihisa Kashima. 2009. "Understanding the Relationship between Attribute- and Metaphor-Based Dehumanization." Group Processes and Intergroup Relations 12: 747-62.

Nussbaum, Martha C. 1995. "Objectification." Philosophy and Public Affairs 24: 49-291.

- 2004. Hiding from Humanity: Disgust, Shame, and the Law. Princeton, NJ: Princeton University Press.

Roberts, Tomi-Ann. 2002. "The Woman in the Body." Feminism and Psychology 12: 324-29.

. 2004. "Female Trouble: The Menstrual Self-Evaluation Scale and Women's Self-Objectification." Psychology of Women Quarterly 28: 22-26.

Roberts, Tomi-Ann, Jamie L. Goldenberg, Cathleen Power, and Tom Pyszczynski. 2002. "'Feminine Protection:' The Effects of Menstruation on Attitudes toward Women." Psychology of Women Quarterly 26: 131-39. 
Roberts, Tomi-Ann, Rachel M. Calogero, and Sarah J. Gervais. 2018. "Objectification Theory: Continuing Contributions to Feminist Psychology." In APA Handbook of the Psychology of Women, edited by Cheryl B. Travis and Jacquelyn W. White, 24971. Washington, DC: American Psychological Association.

Tchekmedyian, Alene. 2019. "Women in Jail Endured Group Strip Searches. L.A. County to Pay \$53 Million to Settle Suit." Los Angeles Times, July 16. https:// www.latimes.com/local/lanow/la-me-ln-lasd-womens-jail-settlement-20190716story.html?fbclid=IwAR0WeK7v474kral8Qk6Hxmnw0LCThBrwZLSyYldQ2GmRZak5-3UF1A_xKTc.

Ussher, Jane. 2006. Managing the Monstrous Feminine. Hove, East Sussex: Routledge. Welten, Stephanie C. M., Marcel Zeelenberg, and Seger M. Breugelmans. 2012. "Vicarious Shame." Cognition ê Emotion 26 (5): 836-46.

Open Access This chapter is licensed under the terms of the Creative Commons Attribution 4.0 International License (http://creativecommons.org/licenses/ by $/ 4.0 /$ ), which permits use, sharing, adaptation, distribution and reproduction in any medium or format, as long as you give appropriate credit to the original author(s) and the source, provide a link to the Creative Commons license and indicate if changes were made.

The images or other third party material in this chapter are included in the chapter's Creative Commons license, unless indicated otherwise in a credit line to the material. If material is not included in the chapter's Creative Commons license and your intended use is not permitted by statutory regulation or exceeds the permitted use, you will need to obtain permission directly from the copyright holder.

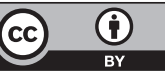

